\title{
SENTIMENTOS E SUGESTÕES MANIFESTADOS POR COLOSTOMIZADOS QUE SE AUTO-IRRIGAM*
}

\author{
Vera Lucia Conceição de G. Santos** \\ Maria Sumie Koizumi***
}

SANTOS, V.L.C. de G.; KOIZUMI, M.S. Sentimentos e sugestões manifestados por colostomizados que se auto-irrigam. Rev. Esc. Enf. USP, v. 26, n. 2, p. 161-72, Ago. 1992.

A análise dos sentimentos $e$ das sugestões apresentadas por um grupo de colostomizados que utilizam um determinado método de auto-irrigação da colostomia para a reeducação do hábito intestinal, mostrou que ele é muito bem aceito por esta clientela. Após a obtenção dos resultados considerados positivos para a auto-irrigação, expressos pela ausência e presença esporádica de perdas fecais $(37,50 \%$ e 42,50\% da população, respectivamente), além da ausência e redução dos gases nos intervalos das irrigações $(27,50 \%$ e $35,00 \%$ da população, respectivamente), $88,14 \%$ dessa clientela referiu sentimentos positivos e a média de sugestöes de $0,35 \%$ por cliente.

UNITERMOS: Colostomia. Irrigação-colostomia. Emoções.

\section{INTRODUÇÃO}

A falta do controle voluntário da defecação, resultante das operações que acarretam o desvio do trânsito intestinal através das colostomias e ileostomias, determina alterações da auto-imagem e imagem corporal do ostomizado, levando a um conjunto de problemas psicológicos e sociais que comprometem profundamente a qualidade de sua vida e suas relações interpessoais $2,3,4,5,6,7,14,17,18,19,20,21$.

Esta imagem do indivíduo sem controle esfincteriano, comprometido tanto em suas necessidades biológicas de eliminação intestinal como psico-sociais, precisa estar clara para os profissionais que o assistem. O objetivo primordial do processo reabilitatório para o ostomizado, em geral, deve ser o de promover uma continência parcial ou transformar o próprio estoma em uma situação aceitável, melhorando a qualidade de vida e promovendo a sua reinserção social ${ }^{13}$.

Neste sentido, diversos estudos têm sido realizados na busca de soluções para o problema da incontinência fecal do ostomizado e suas consequiências e dentre eles, o método da irrigação das colostomias.

\footnotetext{
* Extraido da Monografia de Mestrado, apresentada a Escola de Enfermagem da USP.

* Enfermeira. Assistente do Departamento de Enfermagem Médico-Cirúrgica da EEUSP.

*** Enfermeira. Prof. Doutor do Departamento de Enfermagem Médico-Cirúrgica da EFUSP.
} 
No estudo que realizamos sobre a efetividade da auto-irrigação em 40 colostomizados submetidos a um processo de treinamento por nós sistematizado, constatamos que $37,50 \%$ deles não apresentaram perdas fecais nos intervalos das irrigações e $42,50 \%$ as apresentavam espora. dicamente, totalizando $80,00 \%$ com resultados esperados. Além disso, quanto à presença de gases, ainda nos intervalos das irrigações, 27,50\% referiram não os apresentar e $35,00 \%$ os tinham em menor quantidade. Para o uso da bolsa coletora, 32,50\% relataram nunca empregá-la e $37,50 \%$ somente o faziam em situações específicas, totalizando $2 / 3$ da população com resultados desejados ${ }^{16}$.

Ainda nesse estudo ${ }^{16}$ o paciente foi questionado sobre o que sentia em relação a auto-irrigação e foi mantido um espaço para registrar livremente, suas sugestões.

O presente trabalho tem, pois, como objetivo apresentar e analisar os sentimentos e as sugestões desses pacientes quanto a auto-irrigação da colostomia.

\section{METODOLOGIA}

A população deste estudo constou de 40 colostomizados que se auto-irrigam, utilizando um método ${ }^{15,16}$ por nós padronizado. Por meio de um questionário foi feita a pergunta: "Depois que começou a utilizar a irrigação, como se sente?".

Além do espaço para resposta a esta questão, foi deixado um outro espaço em branco para que o paciente registrasse suas sugestões.

\section{RESULTADOS E DISCUSSÃO}

Os resultados obtidos estão apresentados sob a forma de tabelas, com discussão concomitante.

Os sentimentos dos clientes quanto à auto-irrigação encontram-se reproduzidos integralmente nos Anexos I e II.

TABELA 1 - Respostas dos clientes quanto aos sentimentos relacionados à autoirrigação. São Paulo, 1988.

\begin{tabular}{lrl}
\hline Sentimentos & $\mathrm{N}^{\circ}$ & $\%$ \\
\hline Bem-estar & 30 & 50,85 \\
Segurança & 14 & 23,73 \\
Normalidade & 8 & 13,56 \\
Mal-estar & 7 & 11,86 \\
\hline Total & 59 & 100,00 \\
\hline
\end{tabular}

A tabela 1 mostra as respostas dos clientes quanto aos sentimentos relacionados à utilização da irrigação e categorizados como: bem-estar, 
segurança, normalidade e mal-estar. Essas respostas totalizam 59, com a média de 1,18 sentimentos por cliente.

Verificamos pelos dados obtidos que a maior parte das respostas $(88,14 \%)$ indicam sentimentos positivos: $50,85 \%$ para bem-estar; $23,73 \%$ para segurança e $13,56 \%$ para normalidade.

A criação de um ânus artificial e incontinente na parede abdominal leva o colostomizado a uma alteração de imagem corporal e auto-imagem diretamente ligadas à lesão do próprio soma e perda da habilidade em controlar as eliminações. Isto pode acarretar sentimentos indesejáveis de agonia, inferioridade com redução da auto-estima e desvalorização do autoconceito, insegurança e a crença da rejeição pelos outros indivíduos, com sérias consequiências para os planos afetivo, intelectual e social. Todos esses sentimentos sofrem a influência e também passam a influir na personalidade individual. Outro fator importante é o próprio meio de onde o cliente provem. De maneira geral, entretanto, esses sentimentos quase sempre ocorrem, $\mathrm{m}$ maior ou menor grau $2,4,5,7,10,19,20$.

Assim sendo, o processo de reabilitação do ostomizado deve visar e permitir que ele se torne, o mais precocemente possível, seguro e independente, com um menor grau de ansiedade e conflitos 4,7,13,20.

Ao verificarmos os sentimentos manifestados pelos clientes deste estudo, quanto ao método da irrigação, podemos afirmar que ele se revelou como um dos mecanismos para atingir tal objetivo. Metade da população revela sentimentos de "estar bem", "estar ótimo", "estar muito bem" e "estar excelente" com o uso da auto-irrigação.

A melhora do padrão de vida foi uma resposta mencionada e categorizada como sentimento de bem-estar. Este consiste em um dos maiores objetivos dentro de qualquer processo de reabilitação onde se procura fazer com que o indivíduo tido como "deficiente" desenvolva ao máximo suas potencialidades, voltando a reintegrar-se gradativamente nas atividades de vida diária, desde as mais simples, de maneira qualitativamente adequada.

Segundo ELCOAT 7 , um dos problemas psicológicos que afeta 0 colostomizado é a "fixação pela limpeza", levando o indivíduo a trocar e higienizar frequientemente as bolsas coletoras ou a utilizar perfumes, procurando compensar o receio de estar sujo ou exalando odor desagradável.

Em nosso contato diário com ostomizados em geral, esta é uma manifestação comum mesmo que eles estejam devidamente orientados quanto ao autocuidado e adaptados à bolsa coletora em uso. Portanto, a menção feita por um dos clientes quanto à "sensação de conforto e higiene" promovida pela irrigação, constitui um fator bastante importante, uma vez que esse é comumente um problema sério para o ostomizado. Apesar de termos nos deparado com clientes que manifestassem certa ojeriza na demonstração do procedimento da irrigação por terem que manipular as fezes, isto não ocorreu, conforme vimos, frente 
às respostas dadas, havendo inclusive quem dissesse que a irrigação é um "método limpo de lidar com o estoma".

Reportando-os aos resultados da auto-irrigação, esperados frente ao processo de treinamento proposto, poderíamos antecipar que os sentimentos revelados pelos clientes seriam também positivos. Contudo, não podemos nos esquecer que estes constituem manifestações essen. r,ialmente individuais e, portanto, não mensuráveis dentro de uma visão estritamente quantitativa.

Pessoalmente, considerávamos que aqueles indivíduos que apresentassem rotineiramente perdas fecais nos intervalos das irrigações ou que permanecessem utilizando o coletor, expressariam desagrado e insatisfação, apesar de confiarem no método. Entretanto, isto mostrou ser uma visão do profissional que esperava resultados perfeitos, principalmente por acreditar no método de auto-irrigação e no processo de treinamento proposto.

Assim verificamos que, mesmo aqueles indivíduos com 1 a 2 perdas fecais ao dia entre as irrigações ( 7 clientes), exceto 1 deles, mencionaram sentimentos de bem-estar e segurança. Isto corroborou nossa opinião de que, apesar das perdas, os clientes confiam no método e sentem-se seguros, comparativamente ao período anterior ao treinamento.

Outras respostas como "o esquecimento da colostomia", "ausência de preocupação para sair de casa" e o "tudo sob controle", só reafirmam essa confiança e segurança frente à auto-irrigação.

Algumas outras citações apresentadas na categoria segurança, referem-se à abolição do emprego da bolsa coletora ("só uso a bolsa raramente", "não tenho que preocupar-me com a troca de bolsas" e "sinto-me mais aliviada por não ter que usar a bolsa que gerava irritação na pele e incômodo"). Isto também vai de encontro às nossas constatações de que a maioria dos clientes ou nunca utilizam a bolsa coletora $(32,50 \%)$ ou o fazem somente em situações específicas $(37,50 \%)$.

Para as respostas de normalidade, todos os colostomizados que as mencionam apresentam ausência ou ocorrência ocasional de perdas fecais. Apesar destes sentimentos aparecerem apenas em uma frequiência de $13,56 \%$, é fundamental que tenham surgido, uma vez que todo o processo reabilitatório de qualquer natureza deve objetivar a reintegração do indivíduo às suas atividades normais como no período prédoença, pois somente desta forma ele poderá sentir-se novamente um membro ativo e participante dos núcleos sociais.

No início de nosso trabalho junto a ostomizados, há cerca de 7 anos, frequientemente nos defrontávamos com indivíduos que ao submeterem-se à feitura do estoma, passavam ao isolamento completo, muitas vezes também familiar. Com a organização de centros de tratamento e associações de ostomizados disseminados pelas principais capitais brasileiras; o desenvolvimento de normas e manuais de orientação, fundamentados na realidade nacional; o envolvimento de equipes 
multiprofissionais nessa assistência; a luta junto às autoridades para a criação de legislação específica de distribuição de bolsas coletoras e também o maior emprego de métodos alternativos para o controle do hábito intestinal, entre os quais a auto-irrigação, esse panorama tem se modificado para melhor, pelo menos ao nível das maiores capitais.

Passamos a constatar que os ostomizados têm retornado às suas atividades domésticas, de trabalho e até de lazer, o que também foi possível identificar neste estudo.

Das 59 respostas citadas, apenas $7(11,86 \%)$ revelam sentimentos negativos, nomeados como "mal-estar", embora 3 desses clientes manifestassem estar bem, apesar da resposta dada.

Ao correlacionarmos esses sentimentos de mal-estar com a presença de evacuações entre as irrigações, verificamos que somente 2 clientes com 2 perdas ao dia, apresentam esses sentimentos, sendo que os demais referem perdas fecais ausentes ou esporádicas. Destas citações, apenas 3 relacionam-se a problemas psicológicos de inaceitação da colostomia e depressáo, enquanto que as demais são relativas ao procedimento em si, quanto à sua interferência na rotina diária, falha de ordem técnica e problemas físicos.

Desta feita, ressaltamos mais uma vez a importância de se valorizar a individualidade dos sentimentos frente às situações de vida pessoal como a doença, suas sequielas e os resultados alcançados com quaisquer processos reabilitatórios, o que vem reafirmar a necessidade de um processo assistencial sistematizado e planejado de forma individualizada, que seja implementado desde uma fase pré-operatória até ambulatorial tardia.

A última questão do questionário enviado aos clientes criou para eles um espaço em que eles podiam comentar ou sugerir o que quisessem. Após o levantamento das respostas dadas, constatamos que a maioria referia-se ainda a sentimentos relativos à irrigação, como uma confirmação ou ampliação das citações já feitas.

rABELA 2 - Sugestões dos clientes quanto à auto-irrigacãa. São Paulo, 1988.

\begin{tabular}{lll}
\hline & Sugestões & $\mathbf{N}^{\circ}$ \\
\hline & Técnicas & 9 \\
De divulgação & 3 \\
& Alimentares & 2 \\
\hline & Total & 14 \\
\hline
\end{tabular}

A Tabela 2 mostra as 14 respostas restantes agrupadas como sugestões e por sua vez categorizadas como: técnicas (9), de divulgação (3) e alimentares: (2). A média de sugestões fornecidas por cliente foi de 0,35 . Este fato pode indicar que a clientela considerou como ade- 
quado não só o método da irrigação, o que se evidenciou na positividade dos sentimentos revelados (Tabela 1 ), mas também o próprio processo de treinamento recebido. Quanto a esse aspecto, outros resultados deste trabalho, apresentados em estudo anterior ${ }^{16}$, puderam indicar diretamente a adequação do processo de treinamento, como o padrão de auto-irrigação obtido quanto ao procedimento, similar ao adotado por nós, além do reduzido número tanto de dificuldades apresentadas para a execução do método (4) como das causas técnicas atribuídas às perdas fecais entre as irrigações $(14,29 \%)$.

Entre as sugestões de ordem técnica a maioria restringe-se a comentários da rotina individual para a execução da irrigação (infusão e drenagem) e o material usado posteriormente (gaze, band-aid).

Um dos respondentes revela que a irrigação feita diariamente causava-lhe sensação de enfraquecimento, levando-o a fazê-la em dias alternados o que não só trouxe melhora da sensação como também a redução dos gases. Outro, aumentou a frequiência da auto-irrigação, de 48 para 24 horas, a fim de diminuir o mau odor dos gases.

A "fraqueza" manifestada pelo indivíduo durante ou após a irrigação pode ser consequiente à rápida infusão da água, à sua temperatura muito fria, às irrigações múltiplas ou às condições de debilidade ou desidratação do cliente ${ }^{9}$. A sua correção dependerá da atuação sobre quaisquer das causas apontadas. Nosso cliente indicou satisfatoriamente outra alternativa, que embora implique em maior tempo dispendido diariamente com a irrigação, para ele mostrou-se adequado e o que é mais importante, foi uma resolução planejada de forma independente.

Conforme vimos, para os flatos houve 2 soluções até certo ponto oponentes, contudo, também propostas executadas a nível individual. Alguns fatores contribuem para a formação e o odor dos gases intestinais como a alimentação e alguns medicamentos, além de existirem também os hábitos inadequados durante e entre as refeições. Quanto à irrigação, ela ređuz mecanicamente os gases por diminuir a flora bacteriana presente no cólon, também responsável pela sua produção. No entanto, maiores periodos sem a auto-aplicação do método mostraram-se, algumas vezes, propícios ao aumento de flatos, segundo alguns autores ${ }^{11,12,18}$, e um de nossos clientes.

Um comentário interessante apresentado merece investigação cien. tífica posterior: "o aquecimento da água, até quase a fervura, diminui os gases dissolvidos, tornando a infusão mais fácil e com menores danos".

Outra sugestão técnica apresentada refere-se à redução do tempo de infusão de 1 para 1 minuto, resultando em ausência de dores $e$ do retorno de água limpa na fase de drenagem. Vários participantes deste estucio (9), responderam realizar a infusão em tempo inferior a 5 minutos (de segundos a 3 minutos). Contudo, somente um deles comentou a respeito. Contrariamente a todos os autores e ao esquema 
de treinamento por nós adotado, esses clientes têm-se irrigado desta forma sem complicações e comprometimento dos próprios resultados alcançados, mostrando mais uma vez a importância da individualização em qualquer plano assistencial.

Um dos clientes afirma que uma alimentação adequada associada a um bom treinamento possibilita a auto-irrigação a cada 48 horas. Certamente isto é possível para alguns colostomizados e não é válido como regra geral. Embora o processo de treinamento inicial e a habilidade desenvolvida posteriormente sejam fundamentais para uma boa adaptação ao método, os fatores alimentares e os resultados obtidos com a irrigação são individuais, fazendo-se necessário, portanto, que o próprio colostomizado os reconheça e assim identifique a fre quiência mais adequada para a auto-irrigação.

Outra sugestão mencionada é a ingestão de Imosec para auxiliar nos resultados da irrigação quando o cliente acha que o alimento fará mal. Embora se reconheça o efeito antidiarréico dessa droga, como tal, ela merece indicação, orientação e prescrição médica. A liberdade dietética, como uma das vantagens da irrigação, é uma opção do cliente uma vez que ele é orientado a identificar o efeito dos alimentos sobre o cólon, nas suas eliminações, para que possa controlá-los e assim evitar o uso de medicações para a mesma finalidade.

Toda a adaptação que o colostomizado desenvolve, dentro do processo do autocuidado, é fundamental à medida que reflete o seu envolvimento e participação efetiva, desde que não traga prejuízo próprio. Assim, a sugestão de transformar uma bolsa coletora comum em drenadora e novamente em coletora de uso constante, indica, por um lado, o aproveitamento mais econômico que o cliente pode fazer de um mesmo material e, por outro, o difícil acesso de uma parcela significativa da sociedade a equipamentos específicos, pelo seu alto custo.

A última sugestão de ordem técnica refere-se ao uso de massagens abdominais por 20 minutos após a fase de infusão. A massagem abdominal tem sido incluída como orientação sistemática para os clientes em nosso protocolo de treinamento por constituir uma medida auxiliar que favorece a drenagem mais rápida e eficiente do efluente $1,8,13,18$.

As sugestões relativas à divulgação da irrigação, apesar da baixa incidência (3), denotam preocupação de alguns ostomizados com a desinformação de indivíduos com a mesma problemática e assim, provavelmente, com algumas chances a menos para uma reabilitação adequada. A divulgação por eles proposta foi a nível de outros ostomiza. dos, da classe médica e da própria equipe multiprofissional, subentendida na necessidade de melhorar o atendimento.

Acreditamos que a criação e o desenvolvimento de centros especializados de atendimento a ostomizados constitui um dos meios de divulgação do assunto, além das próprias associações de ostomizados, à medida que acarretam não só a sistematização assistencial interna, como também a elaboração de manuais e a realização de pesquisas e 
cursos que se tornam mecanismos de comunicação a nível da comunidade científica multiprofissional e da sociedade em geral.

As sugestões alimentares restringem-se à indicação de "comida adequada" e "leve e sem gordura" para melhorar os efeitos da irrigação. Sabe-se entretanto, que embora existam alimentos que tradicionalmente acarretam melhora ou piora da função intestinal, ressaltamos que, para o colostomizado em geral e especificamente para aquele que se irriga, esta deve ser uma busca pessoal de um padrão alimentar próprio, igual ou não ao anterior à doença.

De maneira geral as sugestões formuladas explicitamente ou através dos comentários tecidos pelos clientes, ou já fazem parte do processo de treinamento e especificamente da execução técnica, ou merecerão estudos comprobatórios. Quanto à divulgação do método, acreditamos que a nossa participação em um núcleo assistencial específico; a implementação sistematizada do método da auto-irrigação para clientes selecionados, segundo um programa padronizado de atendimento; a elaboração e distribuição de um manual de orientação acerca da irrigação, já existente ${ }^{10}$ e o próprio desenvolvimento deste trabalho, constituem mecanismos efetivos para tal finalidade.

\section{CONCLUSAO}

O estudo sobre os sentimentos dos clientes relacionados à auto-irrigação, como parte dos resultados de seu emprego após um processo de treinamento sistematizado e revelados por 40 clientes colostomizados, permitiu-nos chegar à seguinte conclusão: 88,14\% das 59 respostas mencionadas indicaram sentimentos positivos $(50,85 \%$ para bem-estar; $23,73 \%$ para segurança e $13,56 \%$ para normalidade), denotando a efetividade tanto do método da irrigação para o controle do hábito intestinal em colostomizados como do processo de treinamento empregado.

SANTOS, V.L.C. de G.; KOIZUMI, M.S. Feelings and sugestions expressed by self-irrigation colostomy patients. Rev. Esc. Enf. USP, v. 26, n. 2, p. 161-72, Aug. 1992.

The analysis of feelings and sugestions presented by a group of colostomy patients which use a specific method of colostomy self-irrigation showed that it's well accepted by these patients. After the positive results using this method, we obtained $88,14 \%$ of the positive feelings answers specially weelbeing, safety and normality and an average of 0,35 sugestions per client.

UNITERMS: Emotions. Colostomy. Irrigation-colostomy.

\section{REFERENCIAS BIBLIOGRAFICAS}

1. ABELlaA, M.D.F. Aproximación la astomía. Bov. Rol Enferm., v. 11, n. 118, p. 4-15, 1988.

2. BAUMEL, H. Readaptation des idéostomisés et des colostomisés: stomathérapie. Ann. Gastroentérol. Hépatol., v. 16, n. 4, p. 283-8, 1980. 
3. CANTONE, G. La riabilitazione tardiva del paziente colostomizzato: la nostra esperienza. Minerva Med., v. 76, n. 5, p. 143-7, 1985.

4. CERF, M.; VALLOT, T. Troubles fonctionnels chez les colostomisés. Ann Gastroentérol. Hépatol., v. 16, n. 4, p. 245-53, 1980.

5. COLOSTOMISES, : soins, éducation, relations soignants soignés a l'hôpital. Rev. Infirm., v. 34 , n. 11, p. $20-4,1984$.

6. DONALDSON, D.R.; NORTHOVER, J.M.A. Continent colostomy devi-ces. Surg. Annu., v. 20, p. $145-58,1988$.

7. ELCOAT, C. Stoma care: identifyng paitents problems. Nurs Times, v. 84, n. 8, p. 67-70, 1988.

8. GABRIELLI $F$, et al Risultati dell irrigazione periodica nella riabilitazione del colostomizzato. Minerva Chir., v. 35, n. 21, p. 1649-54, 1980.

9. GOODE, P.S. Colostomy irrigation. In: BROADWELL, D.C.; JACKSON, B.S. Principles of ostomy care. Sain Louis, Mosby, 1982. Cap. 26, p. 369-80.

10. HABR-GAMA, A. et al. Manual para ostomizados: irrigação das colostomias. São Paulo, Núcleo de Assisténcia a Ostomizados do Hospital das Clínicas da Faculdade de Medicina da USP, 1988.

11. MacLEOD, J.H. Colostomy Irrigation: a transatlantic controversy. Dis. Colon Rectum, v. 15, n. 5, p. $357-60,1972$.

12. MAZIER. W.P. et al. Effective colostomy irrigation. Sur. Gynecol. Obstet., v. 142, n. 6, p. 905-9, 1976.

13. PIETRI, P. et al. Riabilitazione dell enterostomizzato. Chir Triven., v. 18, n. 3, p. 421-38, 1978.

14. SANT'ANA, M.H.P. A enfermeira e os estomas. Ent. Novas Dimens., v. 5, n. 2, p. 39-46, 1979.

15. SANTOS, V.L.C. de G. Relato de experiẻncia no treinamento da irrigaçăo intestinal em uma paciente colostomizada. Rev. Paul. Ent., v. 5, n. 2, p. 73-6, 1985.

16. - Estudo sobre os resultados da irrigação em colostomizados submetidos a um processo de treinamento sistematizado. Såo Paulo, 1989, 107 p. Dissertação (Mestrado) - Escola de Enfermagem, Universidade de São Paulo.

17. STANGER, S. Emotional responses stomatology In: TODD, I.P. Intestinal stomas. London, Willians Heinemann, 1978. Cap. 2, p. 182-6.

18. TerRaNOVA, $O$. et al. Irrigrare o non irrigare il colostomizzato? Chir Triven., v. 17, $n$. 3 , p. $270-80,1977$.

19. THOMAS, C. et al. Psychosocial morbidity in the first three months following stoma surgery. J. Psychosom. Res., v. 28, n. 3, p. 251-7, 1984.

20. Velangi. V. Fear fights against a stoma. Nurs. Mirror, v. 150, n. 4, p. IV-XII, 1980. Supplement.

21. ZERBETTO, E.M. Reabilitacåo do paciente ostomizado. Rev. Paul. Enf., v: 0 , n. 0 , p. $16-20,1981$. 


\section{ANEXO I}

Relação das respostas de cada cliente quanto aos sentimentos relacionados à auto-irrigação.

V1 otimamente bem

V2 maior segurança

V3 muito bem - acontecimento maravilhoso

V4 após a S.O. a melhor coisa foi a irrigação

V5 maior segurança, maior confiança, fisicamente melhor (engordei), bemestar

V6 mais confiante, melhora do padrão de vida

V7 bem

V8 muito bem, esqueço-me às vezes da colostomia, sensação de conforto e higiene

V9 ótima, só fico triste quando a irrigação não funciona direito e aumenta gases com o mal cheiro

V10 bem, tudo sob controle e só uso raramente a bolsa

V11 muito bem graças a Deus

V12 péssima, não aceito a colostomia

V13 sensação de bem estar e facilita a retirada de gases

V14 melhor, com maior segurança

V15 normal

V16 bem, apesar de deprimida, ultimamente aceito a S.O. melhor

V17 muito bem, como se isso fosse uma coisa normal

V18 muito bem mesmo

V19 muito bem (não preciso me preocupar quando saio)

V20 regular (sinto-me muito ressecada)

V21 muito bem

V22 muito bem, vida normal, esqueço-me da colostomia

V23 no princípio deprimida

V24 tranquilio, ajo naturalmente, acostumando-me ao ritmo dos dias alternados

V25 bem

V26 mais despreocupado

V27 bem

V28 muito bem

V29 irrigação é eficiente, traz conforto e segurança

V30 bem 
V31 bem melhor (apesar de ter alguma cólica após almoço)

V32 muito bem

V33 muito bem, mais tranquilia

V34 normal, à vontade, nada me preocupa

V35 mais tranquilo (não tenho que me preocupar com troca de bolsas)

V36 excelente, vida normal

V37 bem (com exceção da rotina diária para a irrigação)

V38 bem

V39 bem, maior conforto, vida praticamente normal no trabalho e fora dele

v40 mais aliviado por nåo ter que usar a bolsa que gerava irritação na pele e incomodo 


\section{ANEXO II}

Distribuição das respostas dos clientes quanto aos sentimentos relacionados à auto-irrigação, segundo a categoria.

- BEM-ESTAR: otimamente bem, fisicamente melhor, muito bem, acontecimento maravilhoso, melhor coisa, melhora do padrão de vida, bem, ótima, bemestar, melhor, excelente, conforto, higiene.

- SEGURANÇA: maior segurança, maior confiança, mais confiante, tudo sob controle, uso bolsa raramente, irrigação é eficiente, aliviada por não ter que usar a bolsa que gerava irritação e incômodo, facilita retirada de gases, não preciso preocupar-me quando saio, tranquilo, mais despreocupado, à vontade, nada me preocupa, não tenho que me preocupar com trocas das bolsas.

- NORMALIDADE: como se isso fosse uma coisa normal, vida normal, esqueço-me da colostomia, ajo naturalmente, normal, vida praticamente normal no trabalho e fora dele.

- MAL-ESTAR: péssima, não aceito a colostomia, deprimida, regular, sinto-me muito ressecada, deprimida no princípio, tenho alguma cólica após almoço, interferência da rotina diária para a irrigação, fico triste quando a irrigação não funciona direito e aumenta gases com o mal cheiro. 